\title{
Performance evaluation of wastewater treatment plants under the sewage variations imposed by COVID-19 spread prevention actions
}

\author{
Hamed Yazdian ${ }^{1} \cdot$ Shervin Jamshidi ${ }^{1}$ (D) \\ Received: 28 January 2021 / Accepted: 28 July 2021 / Published online: 13 September 2021 \\ (C) Springer Nature Switzerland AG 2021
}

\begin{abstract}
Coronavirus disease 2019 (COVID-19) and its spread prevention actions (SPAs) have affected a large number of human activities globally in 2020-2021. Temporary lockdowns, stay-at-home policies, movement restrictions, and personal health care actions have relatively changed the daily life routine in urban areas which can eventually affect the characteristics of municipal wastewater (MW). This study evaluates the performance of wastewater treatment plants (WWTPs) during COVID-19 pandemic and related SPAs. This evaluation also considers MW variations in quality and quantity and compares the performance of WWTPs (2020) with earlier data (2015-2019). For this purpose, 23 WWTPs located in Isfahan province, Iran, were chosen as the study area and classified based on their locations, biological treatment unit, and capacities. Results indicate that the inflow of WWTPs increased $20 \%$ on average during SPAs, while the concentrations of COD and BOD in MW decreased 23 and $16 \%$, respectively. Nevertheless, the performance of WWTPs remained rather constant. It is concluded that increasing the dilute domestic proportion of MW, particularly in smaller communities, as a matter of COVID-19 SPAs could not impose adverse impacts on wastewater treatment operations and pollution removal. Different types of secondary treatment units, such as activated sludge, stabilization pond, and aerated lagoon showed stable performances. However, disinfection was enhanced in WWTPs in order to reduce the probability of viral transmission via wastewater for reuse. This study also recommends that the characteristics of MW, and not treated wastewater, can be used as an indicator for coordinating SPAs in similar epidemics. This notification can be helpful for the management of WWTPs and risk control in urban areas.
\end{abstract}

Keywords Coronavirus $\cdot$ Pandemic $\cdot$ Pollution assessment $\cdot$ Wastewater treatment $\cdot$ Water consumption

\section{Introduction}

Severe acute respiratory syndrome coronavirus 2 (SARS-CoV-2) has caused coronavirus disease 2019 (COVID-19) which is declared as a pandemic by WHO on March 2020 [1]. This virus can be transmitted in communities by infected person, mainly through respiratory droplets and direct contact [2]. Thus, spread prevention actions (SPAs), such as temporary lockdowns, stayat-home policies, movement restrictions, and part-time or remote jobs are adopted in communities worldwide. Frequent hand washing with soap is also emphasized as the most appropriate solution to deactivate the virus on hands and reduce the

Shervin Jamshidi

sh.jamshidi@eng.ui.ac.ir

1 Department of Civil Engineering, University of Isfahan, Isfahan, Iran transmission risks. Some other health care recommendations are using masks and ensuring personal hygiene [2].

SPAs and guidelines can change daily life routines and may have short or long-term positive or negative impacts on the environment [3]. According to the literatures, water consumption rate is increased in residential areas [4,5]. The usage of single-use plastic products is increased for personal protection and healthcare purposes [6]. The trends of air quality parameters are changed during lockdowns [7, 8]. Energy consumption and required water footprint for power plant operations are decreased [9]. Noise pollution is mitigated and wild animal behavior is changed due to non-interfering activities of humans in the ecosystem [10]. Yet, there is lack of evidence about the impacts of SPAs on the variations of the quality and quantity of municipal wastewater.

Municipal wastewater (MW) is mainly produced in cities originated from human activities. MW typically includes a mixture of discharges from households, industrial workshops, 
commercial and service activities. Sewerage system conveys MW to wastewater treatment plants (WWTPs). Thus, it would be probable for MW and WWTPs to be affected by coronavirus outbreak. The viral loads of SARS-CoV-2 tracked in faeces and sewage confirm the presence of this infection and its transmission by MW [11-13]. However, dilution may change the measured values in the sewerage system [14]. Therefore, the monitoring of MW and the surveillance of WWTPs are recommended as a tool for early infection identification [15, 16], and coordinating the severity of SPAs [17]. Since MW may be a route of infection transmission, literatures have highlighted the importance of using proper technologies in WWTPs. The application of advanced treatment units based on filtration are an example to mitigate the risks of treated wastewater for reuse $[18,19]$. Disinfection is also emphasized to minimize the probability of infection transmission by treated wastewater [20]. However, monitoring the performance of WWTPs during COVID-19 pandemic is as important as other recommendations. Otherwise, the risks of treated wastewater for reuse increase. A question remains that how effective SPAs are on the characteristics of MW and the performance of WWTPs.

The objective of this research is to evaluate the overall impacts of COVID-19 spread-prevention actions on the characteristics of MW and the performance of WWTPs. The main contribution of this study is that the variations in MW production rate, quality, and pollutant removal efficiency of WWTPs are evaluated for the first time during COVID-19 pandemic and compared with non- pandemic period (2015-2019). For this purpose, 23 WWTPs in center of Iran are surveyed to provide new insights for the improvement of operation and management in WWTPs and mitigate the risks of treated wastewater reuse.

\section{Materials and methods}

\section{Study area}

This research uses the data of the influent (raw MW) and effluent (treated MW) of 23 WWTPs in Isfahan province, centre of Iran. These data are derived in 6 months, March to August 2020 (COVID-19 pandemic period), and compared with data of the same months in 2015-2019 (5-year nonpandemic period). March 2020 is the time when SPAs are officially commenced in national scale while August is usually the ending time of dry weather condition in Iran. Thus, the weather condition and SPAs among the studied areas are rather identical.

Furthermore, these WWTPs are located in 20 cities with the residential population ranging from 2000 to 2 million. Since the medical and sanitation infrastructures are relatively more available in larger cities, the studied areas are classified in two groups. Class A represents WWTPs located in 11 cities and residential areas with population more than 50 thousand. These cities are mostly the centre of industrial, business, and financial activities in the state with relatively suitable access to medical centers. Class B includes WWTPs located in 12 cities and residential areas with smaller population and limited access to modern medical centers.

In this study, WWTPs use three different types of biological treatment units including activated sludge (AS), aerated lagoon (AL), and stabilization ponds (SP). They also have a wide range of capacities for receiving MW. The sewage flowrate ranges between $200 \mathrm{~m}^{3} / \mathrm{d}$ and $200000 \mathrm{~m}^{3} / \mathrm{d}$. Thus, WWTPs are also classified in three groups according to their capacities. WWTPs with the capacity of $5000-30000 \mathrm{~m}^{3} / \mathrm{d}$ are classified as moderate (M). WWTPs which are receiving the sewage flow more than $30000 \mathrm{~m}^{3} / \mathrm{d}$ are classified as large WWTPs (L), while small WWTPs (S) are those facilities that receive sewage flow less than $5000 \mathrm{~m}^{3} / \mathrm{d}$. Figure 1 summarizes the number of studied WWTPs in different classifications.

In the study area, similar to many parts of the world, people are infected by COVID-19 pandemic. Figure 2 illustrates the official aggregated number of newly infected persons from March to October 2020 in the study area, reported by local medical centers. It shows that during 8 months, the number of newly infected persons is increased 20 times which is more attributed to the cities of Class A. Two reasons may cause higher infected number in larger cities. First, the population density and business activities are relatively greater in Class A areas where social distancing is more critical for controlling the transmission of coronavirus. Second, Class B areas have less access to medical centers where the real records may be different far from the official numbers.

Restrictive actions in COVID-19 pandemic have relatively affected some industrial, commercial and service activities in the study area. They may be temporarily inactivated, particularly when lockdown is imposed. A survey in Iran shows that $38 \%$ of whole businesses were completely inactivated on average in spring 2020, while about $40 \%$ of businesses were partially active [21].

\section{Methodology}

This study employs statistical analysis methods to evaluate and compare the effects of restrictive actions on sewage characteristics and the performance of WWTPs. Here, the analysis of variance (ANOVA) models are used by SPSS (version 23) and Minitab (version 19.2) tools to analyze the differences among group means, including year (2015-2019 and 2020), class (A and B), WWTP capacity (S, M and L), and treatment units (AS, AL, and SP). For this purpose, $95 \%$ confidence interval, known as $\mathrm{P}$ value, is determined as the verification index of the differences among group means. 
Fig. 1 Number of WWTPs according to their biological treatment unit (left) and scale (right) in the study area

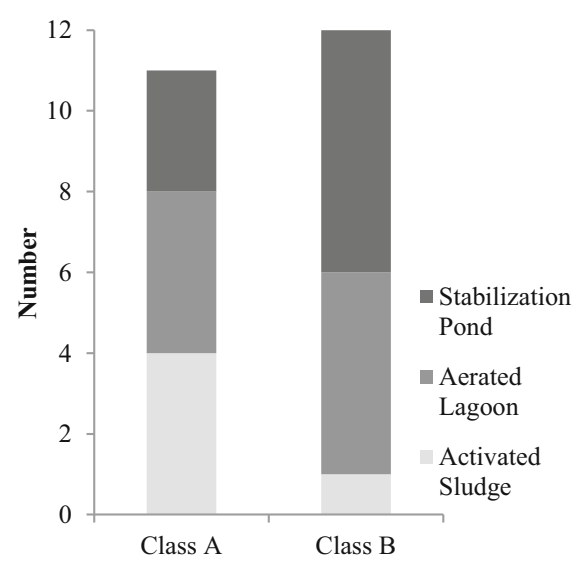

The data used in this study is limited to typical water quality parameters in WWTPs in order to be easily applied or surveyed in different areas in later studies worldwide. Variables are biochemical oxidation demand (BOD), chemical oxidation demand (COD), total suspended solids (TSS), fecal coliform (FC), and wastewater inflow. It also evaluates the biodegradability of wastewater according to the ratio of BOD to COD. Since the flow-rate of MW is specific for any WWTP and ranges widely, the annual growth rate (AGR) is defined as Eq. 1 to account the differences of sewage flow-rate.

$A G R_{i}=\frac{Q_{i}}{Q_{i-1}}$

$A G R_{a}=\frac{\sum_{2016}^{2019} A G R_{i}}{n}$

In these equations, $Q$ refers to the average flow rate of 23 WWTPs $\left(\mathrm{m}^{3} / \mathrm{d}\right), i$ represents the year $(2016,2017,2018,2019$ and 2020), and $n$ equals 4 in this study. By means of these parameters, $A G R$ is calculated for each year with respect to the MW flow-rate of previous year (Eq. 1). For example, $A G R_{2020}$ is the average ratio of the annual growth of $\mathrm{MW}$ inflow in 2020 and 2019. $A G R_{a}$ accounts the average growth rate in

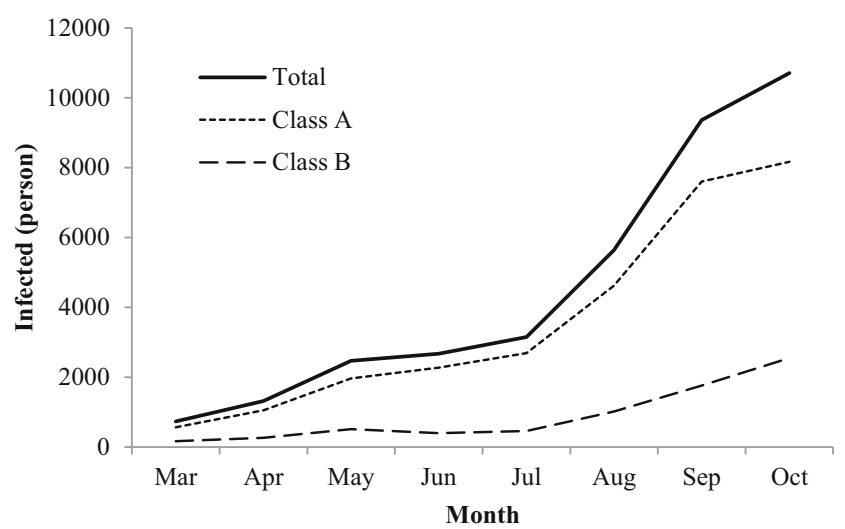

Fig. 2 Aggregated number of coronavirus infected persons in the study area all WWTPs during 2015-2019 (Eq. 2). In other words, $A G R_{2020}$ represents the COVID-19 pandemic period and $A G R_{a}$ refers to non-pandemic period.

\section{Results and discussion}

\section{Wastewater flowrate}

The comparative analysis shows that the average of $A G R_{2020}$ in all WWTPs equals 1.33, while $A G R_{a}$ and $A G R_{2019}$ are 1.12 and 1.14, respectively. The differences of $A G R_{2020}$ with $A G R_{a}$ $(\mathrm{P}=0.032)$ and $A G R_{2019}(\mathrm{P}=0.042)$ are significant with corresponding confidence interval (CI) of $95 \%$. These results reveal that the quantity of $\mathrm{MW}$ is increased $33 \%$ on average in 2020 which is more than the ordinary $A G R_{a}$ of $12 \%$ in 2015-2019. According to the annual reports of National Water and Wastewater Engineering Company (NWWEC) in Iran [22], the serving population of WWTPs in Isfahan province is rather constant (from 2015 to 2019) and grows only $1 \%$ annually (SGA). Therefore, in 2020 people have relatively produced wastewater with higher rates. The difference between $A G R_{2020}(33 \%)$ and $A G R_{a}(12 \%)$ and SGA (1 $\%)$ equals $20 \%$. It can indirectly point to the increasing rate of water consumption in residential areas during COVID-19 pandemic. However, wastewater production rate is higher in Class B. Figure 3 illustrate the average of $A G R$ with its $95 \%$ CIs in different periods and city classifications. $A G R_{2020}$ in class A is 1.27 , while it exceeds 1.37 in class B. The highest AGR before 2020 is 1.18 which was attributed to Class B societies (Fig. 3a). Tukey test is used to simultaneously show the differences of $A G R_{i}$ means. According to Fig. 3b, if an interval does not contain zero line, the corresponding means are significantly different as it is obvious for $A G R_{2020}$. Therefore, SPAs seem to be effective on discharge flow rates. These effects on MW production rate are relatively more in smaller and less populated areas. 

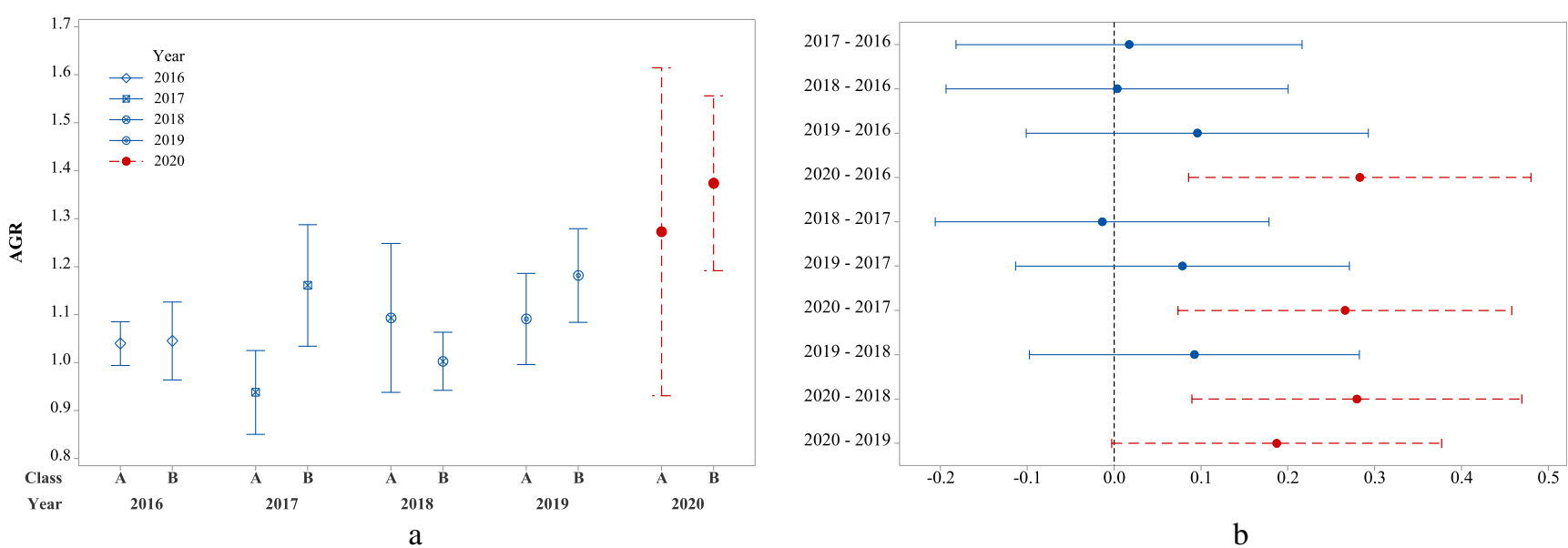

Fig. 3 Means and CIs (95\%) of the AGRs of MW in (a) different periods and city classifications, and (b) compared by Tukey test. Red dashed lines represent $\mathrm{AGR}_{2020}$

\section{Wastewater quality}

An increase in the flow rate of MW may change the concentrations of pollutants, like BOD or COD. The comparative results indicate that the average concentration of COD in MW is reduced significantly from $560 \mathrm{mg} / \mathrm{L}(2015-2019)$ to $431 \mathrm{mg} / \mathrm{L}(2020)$ with the corresponding CI of $99 \%$. It equals $23 \%$ reduction for COD concentration. Likewise, BOD is significantly reduced from 262 to $220 \mathrm{mg} / \mathrm{L}$ (16\% reduction). The concentrations of BOD and COD in smaller communities (class B) are decreased more striking than larger cities (class A). The average concentration of BOD in MW in 2020 is reduced 22 and $9 \%$ in class B and class A, respectively. Likewise, COD is reduced 27 and $18 \%$ in these communities, respectively (Fig. 4). These reductions are due to the fact that higher water consumption for sanitation can dilute pollutants. Closing industrial or business activities, like workshops or restaurants, may also reduce the strength of MW. This conclusion has similarly been reported by Collivignarelli et al. (2020) and Aydin et al. (2021) in air pollution [7, 8]. They concluded that SPAs could temporarily decrease the polluting activities, particularly industries, and reduce the concentration of air pollutants.

Figure 5a illustrates that the COD concentrations of MW in 2020 (COVID-19 period) is significantly lower in comparison with non-pandemic data. According to the results of Tukey test (Fig. 5b), 2020 does not contain zero line with 2017, 2018 and 2019 (red dashed lines). Figure 6 also verifies that the annual and monthly analyses have similar conclusions. The monthly mean of COD concentrations (March-August) in 2020 are less than non-pandemic months. Therefore, possible monthly variations of COD in MW were not as effective as annual variations occurred in 2020 .

The ratio of BOD to COD indicates the biodegradability of MW. Figure 7 shows the proportion of readily biodegradable compounds of raw and treated wastewater in two periods
(2015-2019, and 2020) and city classifications (A, B). Here, the ratio of BOD to COD in MW is remarkably increased from 0.48 (2015-2019) to 0.52 (2020) with corresponding CI of 99 $\%$. This result would possibly be due to SPAs that increase the proportion of domestic wastewater, and conversely reduce industrial high-strength wastewater. However, the biodegradability of treated wastewater remains constant.

Figure 7 indicates that the biodegradability of MW in larger cities (class A) is comparatively less than small communities (class B) in 2015-2019. Nevertheless, this difference is removed in 2020 when the ratio of BOD to COD becomes more identical among these classes. It implies that the lifestyle of people living in both city classes has possibly become more identical during COVID-19 pandemic.

Statistical analysis also reveals that the COD concentration of MW is correlated with the number of infected people. Figure 8 plots the number of newly COVID-19 infected people against the average COD concentration of MW for each month. Here, the number of people is the aggregate of newly

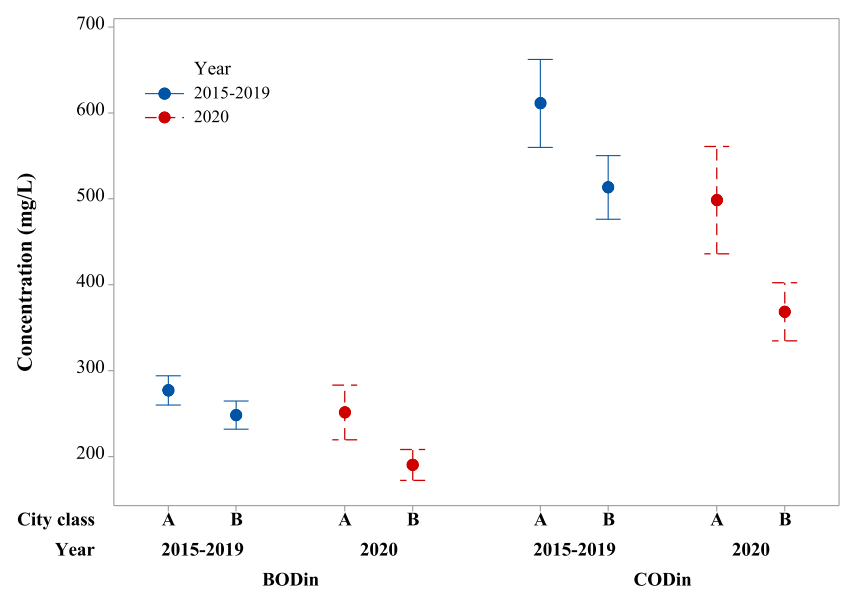

Fig. 4 Means and CIs (95\%) of BOD and COD concentrations $(\mathrm{mg} / \mathrm{L})$ in different periods and city classifications. Red dashed lines represent 2020 data 

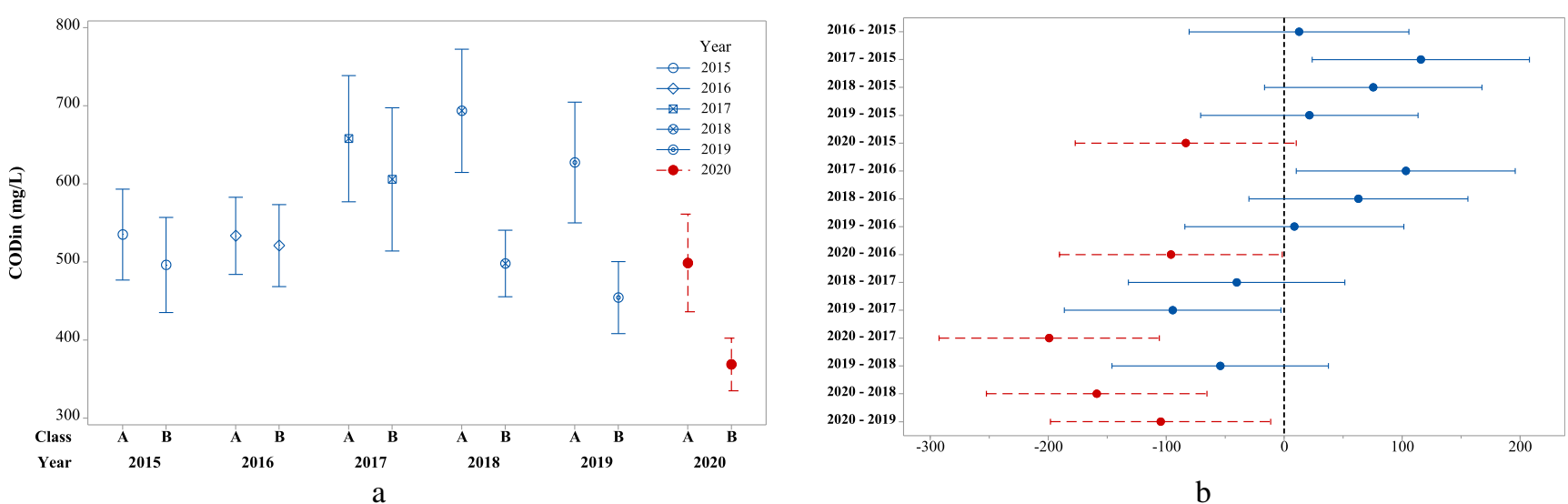

Fig. 5 Means and CIs (95\%) of the COD concentration of MW in (a) different years and city classifications, and (b) compared by Tukey test, Red dashed lines represent CODin (2020)

infected residents for each month living in class A or class B cities. Results show that the COD concentration decreases as the number of infected people increases in large cities (class A) with $\mathrm{R}^{2}=0.84$. On the contrary, COD increases as the number of infected people increases in small communities (class B) with $\mathrm{R}^{2}=0.70$. This would be possibly due to the fact that during COVID-19 pandemic, SPAs may mostly affect the lifestyle in larger cities where industrial and business activities are mainly located. For example, migrant workers and employees stay at home longer due to temporary lockdown and do their jobs more remotely. Similar actions in different businesses and industries in large cities can possibly reduce the proportion of high-strength MW and conversely increase the proportion of low-strength MW. Consequently, the COD concentration of MW converges to about $450 \mathrm{mg} / \mathrm{L}$ in both city classes in severe pandemic conditions (months with higher infected numbers). This conclusion is similarly observed for the biodegradability of MW in 2020.

\section{Performance of wastewater treatment plants}

This study also evaluates and compares the performance of 23 WWTPs in 2015-2020. The comparative results indicate that BOD, COD and TSS removal efficiencies in WWTPs were not significantly changed $(95 \% \mathrm{CI})$ in 2020 and remained rather constant (Fig. 9a). Monthly observations for the performance of WWTPs also approve that the performance of WWTPs were not significantly different in pandemic and non-pandemic periods (Fig. 9b). Therefore, SPAs could not deteriorate the overall performance of WWTPs. In addition, Fig. 9a illustrates that AS was significantly more efficient in BOD, COD and TSS removal in comparison with SP and aerated lagoon AL, in both pandemic and non-pandemic periods.

Table 1 summarizes the statistical analysis of wastewater parameters in 2015-2019 and 2020. Here, the P-value verifies that whether the confidence level reaches to $95 \%(\mathrm{P}<0.05)$ or not. The parameters indicating the performance of
Fig. 6 Means and CIs (95\%) of the COD concentration per months (March-August) in different years

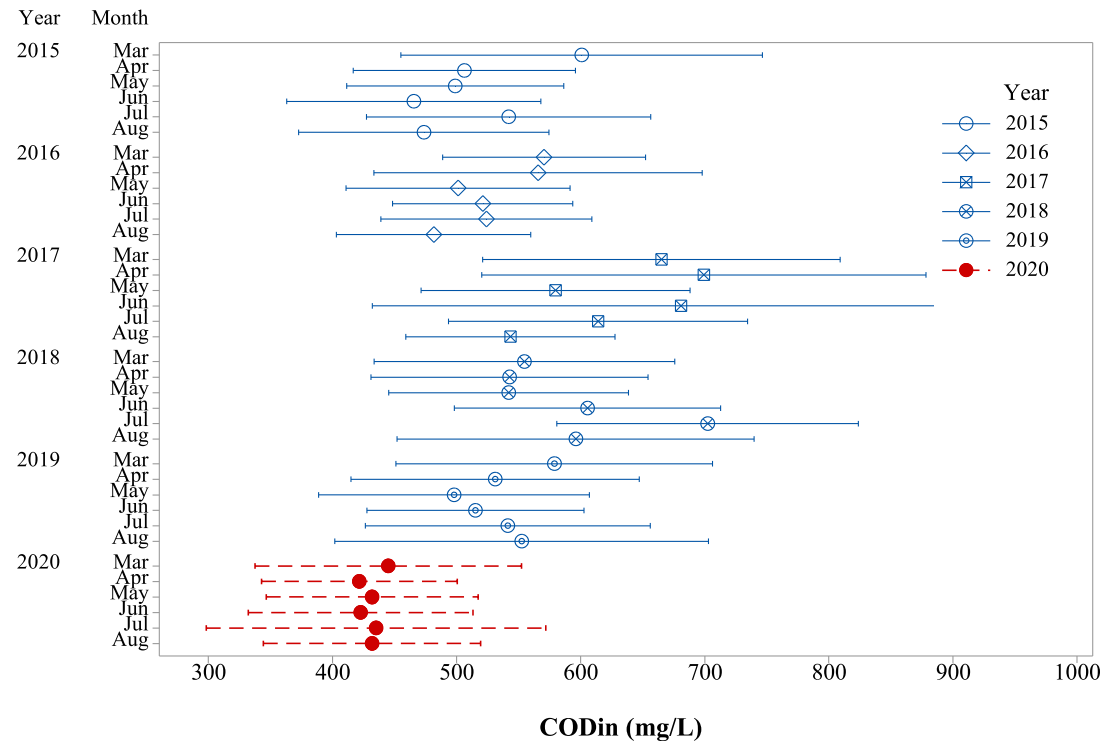


Fig. 7 Mean and CI (95\%) of the biodegradability of raw (in) and treated (out) wastewater in different periods and city classifications

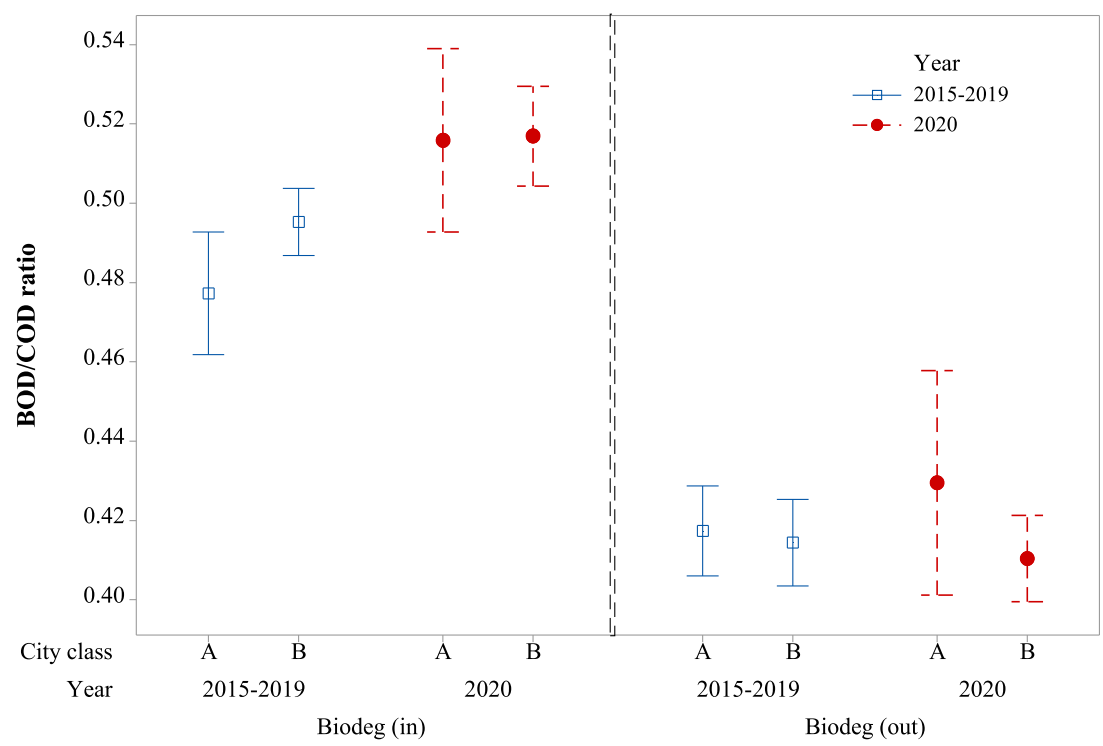

WWTPs, such as COD and TSS removal (\%), show no significant changes in 2020 ( $\mathrm{P}>0.05$ ), while FC of treated wastewater is reduced significantly from 4.5 to $3.6 \log _{10}$. On the contrary, parameters indicating the characteristics of $\mathrm{MW}$, such as COD concentration and the ratio of BOD to COD, are significantly changed in $2020(\mathrm{P}<0.05)$.

Disinfection is typically the final step in wastewater treatment. Different methods can be used to reduce FC from biologically treated wastewater, such as UV radiation, Ozonation, and tertiary treatment with high residence time as in stabilization ponds [1]. However, chlorination is the most prevalent method used in 23 WWTPs studied in this research [23]. This step plays a critical role on reducing the risks of treated wastewater for recycling and reuse. Therefore, operational instructions were developed in 2020 to improve chlorination in the study area. Here, FC of treated wastewater is referred as an index to evaluate the performance of disinfection process in WWTPs.

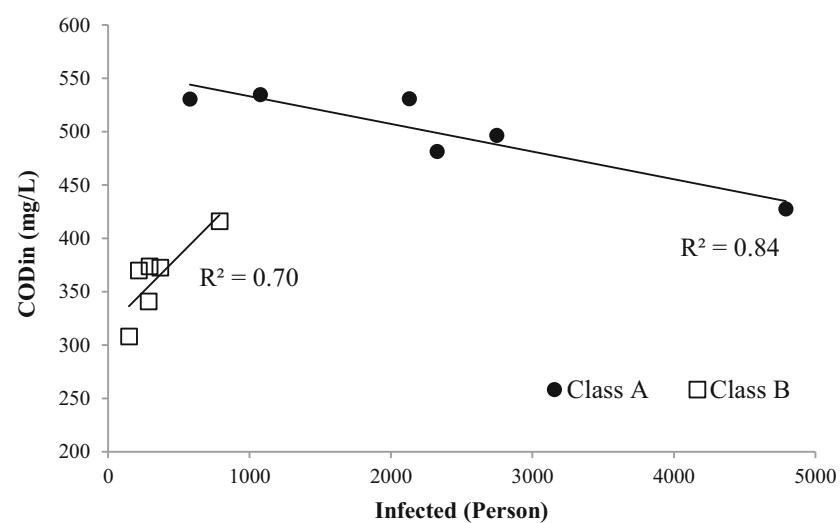

Fig. 8 Correlation between the aggregated number of infected persons living in class A or class B cities and their average COD concentration $(\mathrm{mg} / \mathrm{L})$ of MW in 2020 in each month
According to the results, FC of treated wastewater is reduced about $20 \%$ in 2020 in comparison with its average in 2015-2019 with the corresponding CI of $99 \%(\mathrm{P}=0.00)$. This reduction is more significant in small WWTPs with AL or AS units, and moderate WWTPs with AL or SP (Fig. 10a). The monthly values of $\mathrm{FC}$ also confirm that the operators of WWTPs in the study area have enhanced the disinfection in comparison with non-pandemic period (Fig. 10b). It should be noted that the average FC $\left(\log _{10}\right)$ of studied WWTPs is not suitable and risk-free for recycling and reuse as it should be below $1000\left(3 \log _{10}\right)$ for irrigating non-food crops [24]. However, this assessment emphasizes that disinfection should be noticed during COVID-19 pandemic. Otherwise, the health risks of treated wastewater may increase. Here, the treated wastewater of moderate WWTPs in study area has relatively less health risks according to their FC.

\section{Discussion}

This study concluded that SPAs during COVID-19 pandemic were possibly effective on the characteristics of MW and may have impacts on disinfection units. In this period, MW was more diluted mainly due to the increase of domestic water consumption in addition to the limitations imposed on industrial and commercial activities in urban areas. Kalbusch et al. (2020) have similarly concluded that SPAs reduced industrial and commercial water consumption and conversely increased water consumption in residential areas. In southern Brazil, water consumption reduced between 35 and $65 \%$ in industrial and commercial activities, while it increased $10 \%$ in residential areas during the pandemic period. Hotels, restaurants, and educational centers were some activities with the highest water reduction rate during COVID-19 pandemic [4]. 


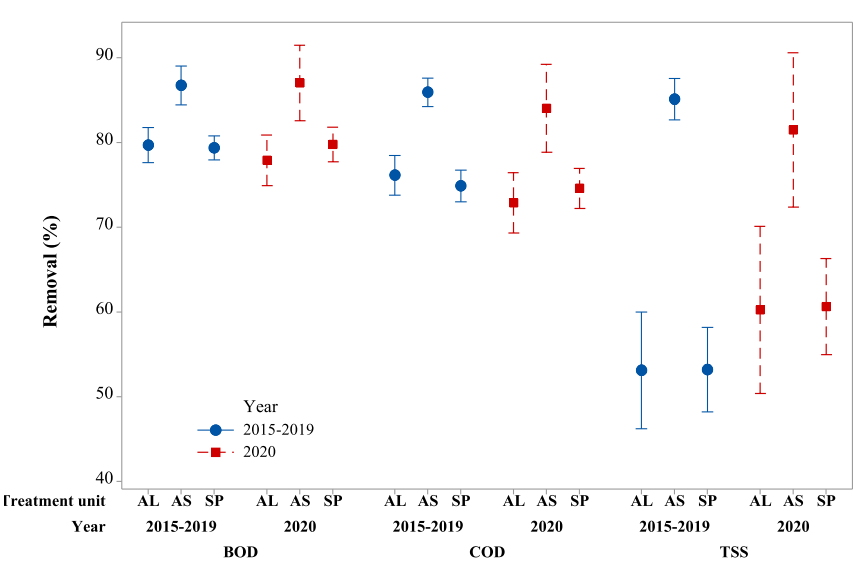

a

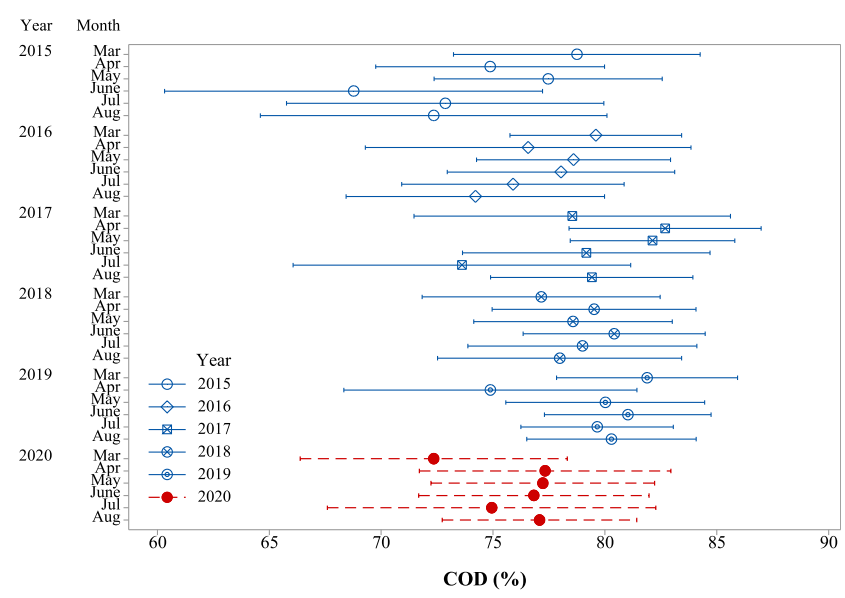

b

Fig. 9 Means and CIs (95\%) of (a) annual BOD, COD, and TSS removal efficiencies (\%) in different periods and biological treatment units, and (b) Monthly COD removal (\%) efficiency in 23 WWTPs. Red dashed lines represent data in 2020

These changes can ultimately change the characteristics of MW. It also implies that the variations of MW are like an indicator that can reflect the behavior or lifestyle of people in urban areas. If SPAs are generally implemented in a city, MW would be possibly changed in quality and quantity. However, it is realized that these variations in MW may not impose considerable risks to the performance of WWTPs in pollution removal. According to Alves et al. (2021) and Cossio et al. (2020) about the reliability and sustainability of WWTPs, respectively, it can be claimed that WWTPs were not be affected considerably during pandemic period $[25,26]$. It is good news for the users of the productions of WWTPs. Jamshidi (2019) concluded that WWTPs can be introduced as reliable urban infrastructures with added values if they are tailor-made, designed and upgraded for local requirements in water, energy and fertilizers [27]. Therefore, even in pandemic periods, WWTPs can be reliable, particularly if appropriate treatment units are used. For example, Balboa et al. (2021) showed that a proper sludge processing, including digestion, can provide COVID-19 risk free products [28].

This study revealed that AS is more effective in BOD, COD, and TSS removal in both pandemic and nonpandemic periods than SPs or ALs. It contradicts the result of a case study by Sharafi et al. (2012) as they concluded that SP is more effective than AS in pollution removal [29]. It is obvious that the deficiency of TSS removal in biological units may disturb the efficiency of posttreatment units like disinfection process in WWTPs.
Table 1 The summary of statistical analysis of variables among two groups of 2015-2019 and 2020

\begin{tabular}{|c|c|c|c|c|c|c|}
\hline Parameter & Groups & Mean & Std. Deviation & Std. Error & $\mathrm{F}$ & $\begin{array}{l}\text { P- } \\
\text { value }\end{array}$ \\
\hline \multirow[t]{2}{*}{ BOD (in) } & 2015-2019 & 262.2 & 109.94 & 4.235 & 16.34 & 0.000 \\
\hline & 2020 & 219.6 & 104.76 & 9.296 & & \\
\hline \multirow[t]{2}{*}{ COD (in) } & 2015-2019 & 560.1 & 282.65 & 10.887 & 24.08 & 0.000 \\
\hline & 2020 & 431.0 & 205.90 & 18.271 & & \\
\hline \multirow[t]{2}{*}{$\%$ BOD removal } & 2015-2019 & 81.1 & 11.24 & 0.431 & 0.17 & 0.680 \\
\hline & 2020 & 80.7 & 10.22 & 0.900 & & \\
\hline \multirow[t]{2}{*}{$\%$ COD removal } & 2015-2019 & 77.8 & 12.58 & 0.482 & 2.12 & 0.146 \\
\hline & 2020 & 76.0 & 12.08 & 1.064 & & \\
\hline \multirow[t]{2}{*}{$\%$ TSS removal } & 2015-2019 & 60.2 & 36.53 & 1.401 & 2.13 & 0.144 \\
\hline & 2020 & 65.2 & 28.56 & 2.515 & & \\
\hline \multirow[t]{2}{*}{$\mathrm{BOD} / \mathrm{COD}$ (in) } & 2015-2019 & 0.49 & 0.08 & 0.003 & 13.89 & 0.000 \\
\hline & 2020 & 0.52 & 0.07 & 0.006 & & \\
\hline \multirow[t]{2}{*}{$\mathrm{BOD} / \mathrm{COD}$ (out) } & 2015-2019 & 0.42 & 0.08 & 0.003 & 0.17 & 0.682 \\
\hline & 2020 & 0.42 & 0.08 & 0.007 & & \\
\hline \multirow[t]{2}{*}{$\mathrm{FC}_{\mathrm{eff}}\left(\log _{10}\right)$} & 2015-2019 & 4.5 & 1.37 & 0.055 & 43.24 & 0.000 \\
\hline & 2020 & 3.6 & 1.70 & 0.152 & & \\
\hline
\end{tabular}



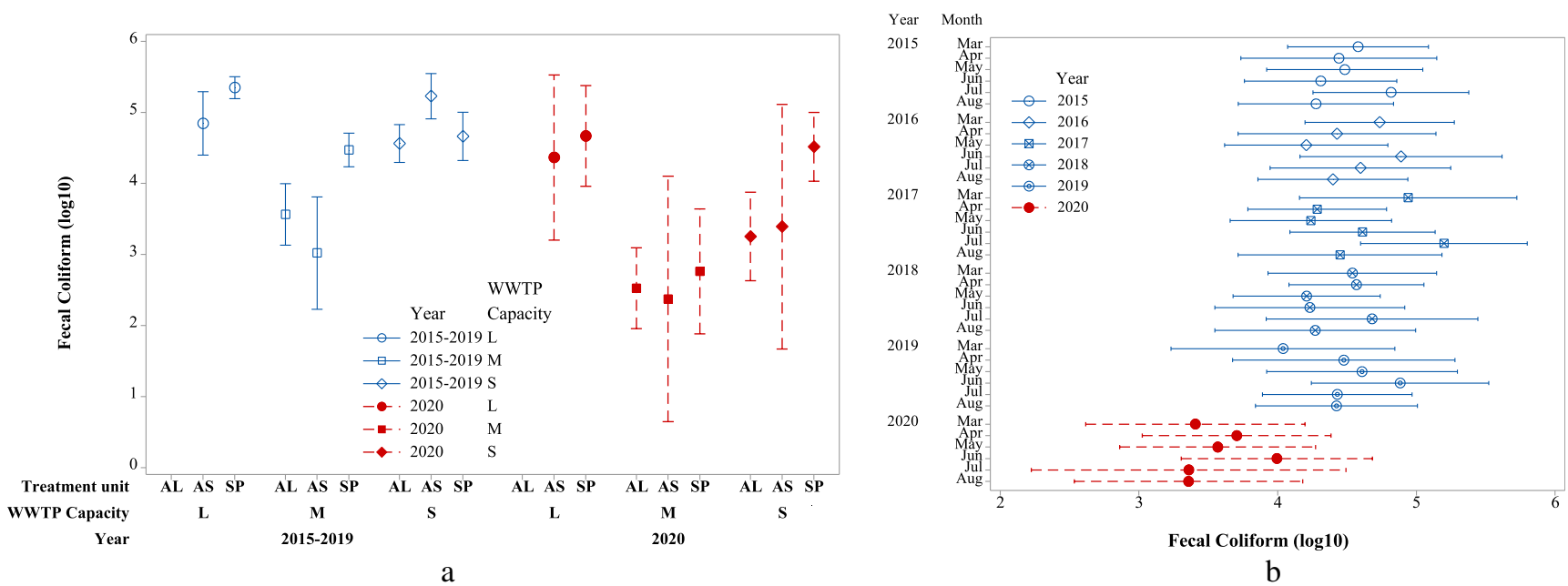

Fig. 10 Mean and CIs $(95 \%)$ of the FC ( $\log 10)$ of treated wastewater in (a) different years, treatment units, and capacities of WWTPs, and (b) months (March-August) in study period. Red dashed lines represent data in 2020

Since disinfection can reduce pathogens or viruses, its deficiency can impose risks on wastewater reuse during the pandemic $[1,30]$. Proper disinfection and TSS control in treated wastewater are two primary recommendations by Chen et al. (2021) [31]. They emphasized that the application of advanced treatment units can decrease the risks of surviving coronavirus in treated wastewater. Randazzo et al. (2020) revealed that $11 \%$ of SARSCoV-2 samples in secondary treated wastewater is positive, while it is removed in tertiary treated wastewater [17].

Three policies are recommended for COVID-19 post-pandemic era. First, water consumption should not remain at high rate in the study area. Second, WWTPs should be prepared for high-strength discharges from industrial activities. Reopening of restaurants or industrial workshops can increase the COD concentration of MW. These trends are similarly observed in other environmental concepts, like air pollution by Aydin et al. (2021) [8]. SPAs temporarily improve the air quality during COVID-19. However, lifting the restrictions will considerably increase the emissions [3, 32]. Third, WWTPs should be equipped with advanced or tertiary treatment units, to reduce the health and environmental risks of treated wastewater, particularly for similar pandemic crisis [33]. It is noteworthy that the impacts of COVID-19 on environment in the long term are still uncertain. According to Pandey et al. (2020), These effects may be also variable in developing countries, depending on the awareness of the risks of using raw or treated wastewater [34]. In addition, these effects are case specific [35]. Therefore, further studies are required to assess the overall impacts of SPAs on water consumption, MW production, its quality, the operation of WWTPs, and the risks of using treated wastewater during pandemics as similarly recommended by Rahimi et al. (2021) [36]. They highlighted that the impacts of COVID-19 outbreaks were mostly assessed for air pollution and airborne transmissions globally, while other environments, like water and wastewater, requires more comprehensive analysis.

\section{Conclusions}

This study assessed the short-term effects of SPAs on the characteristics of MW and the performance of WWTPs. According to the statistical analysis, the following conclusions are highlighted:

- SPAs can possibly increase the quantity of MW, mainly due to an increase in water consumption for sanitation and personal hygiene and decrease in industrial and commercial purposes. Smaller and less populated cities may relatively experience higher growth rate of MW.

- The concentration of BOD and COD in MW decrease during COVID-19 pandemic. SPAs and related restrictions imposed on industrial workshops can possibly reduce the strength of MW and increase its biodegradability, particularly in populated areas. It is also realized that COD concentration in MW can be used as an index for coordinating SPAs as it correlates with the infected number of people.

- The performance of secondary treatment unit for pollution removal is constant. However, disinfection is improved for the reduction of probable risks of wastewater reuse. Treated wastewater discharged from moderate WWTPs has comparatively less health risks for reuse.

- Further studies are recommended to assess the impacts of SPAs in long-term. These types of studies can improve scientific and applied knowledge about the proper operation of WWTPs and coordination of SPAs. It also may develop a new risk-based definition or methodology for the management of treated wastewater for reuse, particularly in pandemic periods. 


\section{Declarations}

Conflict of interest The authors declare that they have no known competing financial interests or personal relationships that could have appeared to influence the work reported in this paper.

\section{References}

1. Mandal P, Gupta AK, Dubey BK. A review on presence, survival, disinfection/removal methods of coronavirus in wastewater and progress of wastewater-based epidemiology. J Environ Chem Eng. 2020;8(5):104317.

2. WHO. Water, sanitation, hygiene and waste management for the COVID-19 virus: Interim guidance. Geneva: World Health Organ.; 2020(April). pp. 1-9.

3. Klemeš JJ, Fan Y, Van, Jiang P. The energy and environmental footprints of COVID-19 fighting measures - PPE, disinfection, supply chains. Energy. 2020;211:118701.

4. Kalbusch A, Henning E, Brikalski MP, de Luca FV, Konrath AC. Impact of coronavirus (COVID-19) spread-prevention actions on urban water consumption. Resour Conserv Recycl. 2020;163:105098.

5. Luke E, Smull E, Patterson L, Doyle M. COVID-19 impacts on water utility consumption and revenues through June 2020. RAFTELIS / DUKE Univ; 2020. pp. 1-5.

6. Sharma HB, Vanapalli KR, Cheela VS, Ranjan VP, Jaglan AK, Dubey B, et al. Challenges, opportunities, and innovations for effective solid waste management during and post COVID-19 pandemic. Resour Conserv Recycl. 2020;162:105052.

7. Collivignarelli MC, Abbà A, Bertanza G, Pedrazzani R, Ricciardi P, Carnevale Miino M. Lockdown for CoViD-2019 in Milan: What are the effects on air quality? Sci Total Environ. 2020;732:139280.

8. Aydın S, Nakiyingi BA, Esmen C, Güneysu S, Ejjada M. Environmental impact of coronavirus (COVID-19) from Turkish perceptive. Environ Dev Sustain. 2021;23:7573-7580.

9. Roidt M, Chini CM, Stillwell AS, Cominola A. Unlocking the impacts of COVID-19 lockdowns: Changes in thermal electricity generation water footprint and virtual water trade in Europe. Environ Sci Technol Lett. 2020;7(9):683-9.

10. Bar H. COVID-19 lockdown: animal life, ecosystem and atmospheric environment. Environ Dev Sustain. 2021;23:8161-8178.

11. Amoah ID, Kumari S, Bux F. Coronaviruses in wastewater processes: Source, fate and potential risks. Environ Int. 2020;143:105962.

12. Elsamadony M, Fujii M, Miura T, Watanabe T. Possible transmission of viruses from contaminated human feces and sewage: Implications for SARS-CoV-2. Sci Total Environ. 2021;755:142575.

13. Lahrich S, Laghrib F, Farahi A, Bakasse M, Saqrane S, El Mhammedi MA. Review on the contamination of wastewater by COVID-19 virus: Impact and treatment. Sci Total Environ. 2021;751:142325.

14. Foladori P, Cutrupi F, Segata N, Manara S, Pinto F, Malpei F, et al. SARS-CoV-2 from faeces to wastewater treatment: What do we know? A review. Sci Total Environ. 2020;743:140444.

15. El-Baz LMF, Elwakeel KZ, Elgarahy AM. COVID-19 from mysterious enemy to an environmental detection process: a critical review. Innov Infrastruct Solut. 2020;5(3):84.

16. Ahmed W, Bertsch PM, Bibby K, Haramoto E, Hewitt J, Huygens F, et al. Decay of SARS-CoV-2 and surrogate murine hepatitis virus RNA in untreated wastewater to inform application in wastewaterbased epidemiology. Environ Res. 2020;191:110092.

17. Randazzo W, Truchado P, Cuevas-Ferrando E, Simón P, Allende A, Sánchez G. SARS-CoV-2 RNA in wastewater anticipated COVID-19 occurrence in a low prevalence area. Water Res. 2020;181:115942.
18. Bogler A, Packman A, Furman A, Gross A, Kushmaro A, Ronen A, et al. Rethinking wastewater risks and monitoring in light of the COVID-19 pandemic. Nat Sustain. 2020;3:981-990.

19. Tetteh EK, Amankwa MO, Armah EK, Rathilal S. Fate of covid-19 occurrences in wastewater systems: Emerging detection and treatment technologies - a review. Water. 2020;12(10):1-20.

20. Kataki S, Chatterjee S, Vairale MG, Sharma S, Dwivedi SK. Concerns and strategies for wastewater treatment during COVID19 pandemic to stop plausible transmission. Resour Conserv Recycl. 2021;164:105156.

21. Shabak A. The effects of Coronavirus on Iranian businesses (In persian) [Internet]. 2020. Report EC-3-2-99-16. Available from: https://srtc.ac.ir/Portals/0/Covid\%20_19_\%20990331_2.pdf. Accessed 8 Sep 2021.

22. NWWEC. Statistical yearbook of water and wastewater industry in Urban Areas (In Persian). National Water and Wastewater Engineering Company, Ministry of Energy, Iran, 2019.

23. Horlemann L, Mohajeri S. Reviving the dying giant: Integrated water resource management in the Zayandeh Rud catchment, Iran. Reviving Dying Giant Integr Water Resour Manag Zayandeh Rud Catchment, Iran. 2017. pp. 1-268.

24. Shoushtarian F, Negahban-Azar M. World wide regulations and guidelines for agriculturalwater reuse: A critical review. Water. 2020;12(4):971.

25. Cossio C, Norrman J, McConville J, Mercado A, Rauch S. Indicators for sustainability assessment of small-scale wastewater treatment plants in low and lower-middle income countries. Environ Sustain Indic. 2020;6:100028.

26. Alves MS, Silva FJA da, Araújo ALC, Pereira EL. Performance evaluation and coefficients of reliability for waste stabilization ponds in northeast Brazil. Ambient e Agua - An Interdiscip J Appl Sci. 2021;16(1):1.

27. Jamshidi S. Value-added innovation in infrastructure systems, lessons learned from wastewater treatment plants. TQM J. 2019;31(6):1049-63.

28. Balboa S, Mauricio-Iglesias M, Rodriguez S, Martínez-Lamas L, Vasallo FJ, Regueiro B, et al. The fate of SARS-COV-2 in WWTPS points out the sludge line as a suitable spot for detection of COVID19. Sci Total Environ. 2021;772:145268.

29. Sharafi K, Davil M, Heidari M, Almasi A, Taheri H. Comparison of conventional activated sludge system and stabilization pond in removal of chemical and biological parameters. Int J Environ Health Eng. 2012;1(1):38.

30. Dias DFC, Passos RG, von Sperling M. A review of bacterial indicator disinfection mechanisms in waste stabilisation ponds. Rev Environ Sci Biotechnol. 2017;16(3):517-39.

31. Chen C, Hayward K, Khan SJ, Örmeci B, Pillay S, Rose JB, et al. Role of wastewater treatment in COVID-19 control. Water Qual Res J. 2021;56(2):68-82.

32. Gillingham KT, Knittel CR, Li J, Ovaere M, Reguant M. The shortrun and long-run effects of Covid-19 on energy and the environment. Joule. 2020;4(7):1337-41.

33. Jamshidi S, Niksokhan MH. Upgrading wastewater treatment plants based on reuse demand, technical and environmental policies (A case study). Environ Energy Econ Res. 2017;1(2):219-30.

34. Pandey D, Verma S, Verma P, Mahanty B, Dutta K, Daverey A, et al. SARS-CoV-2 in wastewater: Challenges for developing countries. Int J Hyg Environ Health. 2021;231:113634.

35. Wang P, Chen K, Zhu S, Wang P, Zhang H. Severe air pollution events not avoided by reduced anthropogenic activities during COVID-19 outbreak. Resour Conserv Recycl. 2020;158:104814.

36. Rahimi NR, Fouladi-Fard R, Aali R, Shahryari A, Rezaali M, Ghafouri $\mathrm{Y}$, et al. Bidirectional association between COVID-19 and the environment: A systematic review. Environ Res. 2021;194:110692.

Publisher's Note Springer Nature remains neutral with regard to jurisdictional claims in published maps and institutional affiliations. 